\title{
How fast does wasp venom immunotherapy affect a regulatory $T$ cell subpopulation (CD4+ CD25+ Foxp3+) and the synthesis of interleukins 10, 21 and transforming growth factor $\beta 1$ ?
}

\author{
Aleksander Zakrzewski ${ }^{1}$, Jerzy Kruszewski ${ }^{1}$, Andrzej Chciałowski², Krzysztof Kłos ${ }^{1}$, Agnieszka Rzeszotarska², \\ Jolanta Korsak², Ewa M. Nowosielska ${ }^{3}$, Aneta Cheda ${ }^{3}$, Jolanta Wrembel-Wargocka ${ }^{3}$, Marek K. Janiak ${ }^{3}$ \\ ${ }^{1}$ Department of Infectious Diseases and Allergology, Military Institute of Medicine, Warsaw, Poland \\ ${ }^{2}$ Department of Clinical Transfusiology, Military Institute of Medicine, Warsaw, Poland \\ ${ }^{3}$ Department of Radiobiology and Radiation Protection, Military Institute of Hygiene and Epidemiology, Warsaw, Poland \\ Adv Dermatol Allergol 2019; XXXVI (1): 82-85 \\ DOI: https://doi.org/10.5114/ada.2019.82828
}

\begin{abstract}
Introduction: The literature describes the influence of venom immunotherapy (VIT) on the subpopulation of T regulatory cells (CD4+ CD25+ Foxp3+) and the synthesis of IL-10, TGF- $\beta 1$ as well as many other cytokines at various times after immunotherapy.

Aim: To assess changes in the percentage of cells of CD4+ and CD25+ in peripheral blood and serum concentrations of IL-10, IL-21 and TGF- $\beta 1$ in the early stages of VIT.

Material and methods: The study included 18 patients who were allergic to wasp venom and who in the past underwent systemic anaphylactic reaction after stinging, meeting the criteria to qualify for VIT. The immunoenzymatic method (ELISA) was used to assess concentrations of cytokines IL-10, IL-21 and TGF- $\beta 1$ and the surface antigens CD4 and CD25 on the cells. The concentrations were determined by flow cytometry method at baseline (before VIT) and after 2.5 and $24 \mathrm{~h}$ from the VIT starting point.

Results: The mean values of the activity of T lymphocytes CD4+ CD25+ FoxP3+ and concentrations of the cytokines IL-10, IL-21 and TGF- $\beta 1$ are shown in table.

Conclusions: A 24-hour activation assessment of serum concentrations of cytokines IL-10, IL-21 and TGF- $\beta 1$ during the first day of the Hymenoptera venom immunotherapy by ultra-rush protocol does not show the significant dynamics of change of the examined parameters.
\end{abstract}

Key words: cytokines, regulatory cells, Hymenoptera venom immunotherapy.

\section{Introduction}

The creation of tolerance during stinging insect venom immunotherapy (VIT) is a complex process associated with the simultaneous launch of several mechanisms both at the level of regulating the function of $T$ and $B$ lymphocytes and the activation of effector cells and the reactivity of the effector organs. The literature describes the influence of VIT on the subpopulation of T regulatory cells (CD4+ CD25+ Foxp3+) and the synthesis of interleukin 10 (IL-10), transforming growth factor $\beta 1$ (TGF- $\beta 1$ ) as well as many other cytokines at various times after immunotherapy [1-7].

\section{Aim}

The aim of our study was to assess changes in the percentage of cells of CD4+ and CD25+ in peripheral blood and serum concentrations of IL-10, IL-21 and TGF- $\beta 1$ in the early stages of VIT.

\section{Material and methods}

\section{Study group}

The study included 18 patients ( 7 men aged $32 \pm 3$ and 11 women aged $45 \pm 8$ ), who were allergic to wasp venom and who in the past underwent systemic anaphylactic

Address for correspondence: Aleksander Zakrzewski MD, PhD, Department of Infectious Diseases and Allergology, Military Institute of Medicine, 128 Szaserów St, 04-141 Warsaw, Poland, phone: +48 261817 197, e-mail: azakrzewski@wim.mil.pl Received: 17.02.2016, accepted: 13.12.2017. 
Table 1. Scheme of the study

\begin{tabular}{lccccccc}
\hline Taking a blood sample & $\mathrm{V}$ & & & $\mathrm{V}$ & $\mathrm{V}$ \\
\hline Time $[\mathrm{h}]$ & 0 & 0.5 & 1 & 1.5 & 2.5 & 3.5 & 24 \\
\hline Concentration $[\mu \mathrm{g} / \mathrm{ml}]$ & 0.1 & 1 & 10 & 20 & 30 & 40 & \\
\hline Dose taken $[\mathrm{ml}]$ & 0.1 & 0.1 & 1 & 2 & 3 & 4 \\
\hline Total dose $[\mu \mathrm{g}]$ & & & & & 61.1 & 101.1 \\
\hline
\end{tabular}

reaction after stinging, meeting the criteria to qualify for VIT, after previous allergy diagnosis established according to the European Academy of Allergology and Clinical Immunology (EAACI) and gave informed written consent to participate in the study.

The VIT was led by the ultra-rush protocol with Venomenhal wespe vaccine (HAL Allergy B.V., the Netherlands). A detailed treatment plan and schedule of the study are presented in Table 1. The day before and on the day of the start of treatment respondents took $10 \mathrm{mg}$ of cetirizine orally (Zyrtec, UCB, Belgium). Blood samples for laboratory tests were taken before $(\mathrm{O} h)$ and after $2.5(2.5 \mathrm{~h})$ and 24 (24 h) h from VIT initiation.

\section{Preparation and peripheral blood cell culture}

Surface antigens CD4 and CD25 on the cells were determined by flow cytometry method using a FACSCanto flow cytometer II (Becton Dickinson). Venous blood was taken on EDTA.

Cells were labeled by direct staining method with monoclonal antibodies coupled with fluorochromes (FITC, PR, APC). The following antibodies were used for the determination of antigens: CD4 FITC (BD), CD25 APC (BD) and Buffer Set FoxP3 PE (BD Pharmingen). Isotype controls with the appropriate fluorochromes were included in each series of test tubes.

After incubation with antibodies, red blood cells were subjected to lysis using lysis buffer BD Pharm Lyse (BD). Then, the samples were washed with PBS and suspended in appropriate buffers which were in the kit. Cytometry marking was performed immediately after finishing the above procedure. 10,000 cells were counted. The analysis of the material was carried out using BD FACSDiva software.

\section{Cytokines}

Blood samples which were taken to determine the concentration of TGF- $\beta 1$, IL-10, IL-21, were centrifuged at $40^{\circ} \mathrm{C}$ at $2600 \mathrm{rpm}$ for $15 \mathrm{~min}$. Serum was transferred to well-described dry test tubes and frozen at $-80^{\circ} \mathrm{C}$ in case of TGF- $\beta 1$ sign and $-25^{\circ} \mathrm{C}$ for the determination of IL-10 and IL-21. Cytokine concentrations were determined by enzyme-linked immunosorbent assay (ELISA method) using a shaker with the function of the Awareness Stat Fax 2200 incubator, washer for ELISA tests (ETI-System DiaSorin) and BioTek ELX 800 reader. To determine the con- centration of TGF- $\beta 1$ and IL-10, Quantikine Human Immunoassay (R\&D Systems Inc., USA) sets were used, by contrast IL-21 was determined by Human IL-21 Platinum ELISA set (eBioscience, Inc., USA). Markings were made in accordance with the procedures recommended by the manufacturers. The concentration levels of the marked cytokines were determined based on the standard curves typical of each set:

- Quantikine R\&D Systems set had a minimum amount detectability of TGF- $\beta 1$ in serum of $1.7-15.4 \mathrm{pg} / \mathrm{ml}$ (mean: $4.61 \mathrm{pg} / \mathrm{ml}$ ), whereas the maximum was 2000 $\mathrm{pg} / \mathrm{ml}$, the coefficient of variation (CV\%) between the sets (Inter-assay), for low concentrations of the particles in serum - less than $100 \mathrm{pg} / \mathrm{ml}$ was less than $9.1 \%$, - Quantikine Human IL-10 Immunoassay R\&D Systems set had a minimum amount detectability of IL-10 in serum of $3.9 \mathrm{pg} / \mathrm{ml}$ and a maximum of $500 \mathrm{pg} / \mathrm{ml}$, the coefficient of variation (CV\%) between sets (Inter-assay), for low concentrations of the particles in serum - less than $100 \mathrm{pg} / \mathrm{ml}$ was less than $7.5 \%$,

- eBioscience Human IL-21 ELISA Platinum set had a minimum amount detectability of IL-21 in serum of 20 pg/ $\mathrm{ml}$ and a maximum of $5000 \mathrm{pg} / \mathrm{ml}$, the coefficient of variation (CV\%) between sets (Inter-assay) for particles in the serum was on average less than $7.7 \%$.

\section{Statistical analysis}

Statistical analysis was performed using Statistica 10 (StatSoft, Inc. USA) program. Due to the distribution, which did not differ significantly from the normal standard, parametric $t$-test was used for dependent samples and the mean as well as the standard deviation of the mean were used for description. Differences for which $p<0.05$ were considered statistically significant.

The study protocol was approved by the Bioethics Committee of the Military Institute of Medicine.

\section{Results}

Peripheral activity of T lymphocytes CD4+ CD25+ and concentrations of the cytokines IL-10, IL-21 and TGF- $\beta 1$ were carried out in serum of 18 tested patients before treatment (baseline) and during treatment $2.5 \mathrm{~h}$ (time of $2.5 \mathrm{~h}$ ) and $24 \mathrm{~h}$ after the administration of the full dose of vaccine, i.e. $101.1 \mathrm{mg}$ of an insect venom (time $24 \mathrm{~h}$ ).

The mean values of the activity of T lymphocytes CD4+ CD25+ FoxP3+ and concentrations of the cytokines IL-10, 
A. Zakrzewski, J. Kruszewski, A. Chciałowski, K. Kłos, A. Rzeszotarska, J. Korsak, E.M. Nowosielska, A. Cheda, J. Wrembel-Wargocka, M.K. Janiak

Table 2. Concentrations of cytokines IL-10, IL-21, TGF- $\beta 1$ and activity of lymphocytes CD4+ CD25+ Foxp3 before and after Hymenoptera venom immunotherapy using the quick method

\begin{tabular}{lcccc}
\hline Time $[\mathrm{h}]$ & \multicolumn{3}{c}{ Interleukins, mean \pm SD } & $\begin{array}{c}\text { Lymphocytes } \pm \text { SD (\% of cells) } \\
\text { CD4+ CD25+ }\end{array}$ \\
\cline { 2 - 4 } & $\mathrm{IL}-10[\mathrm{pg} / \mathrm{ml}]$ & $\mathrm{IL}-21[\mathrm{pg} / \mathrm{ml}]$ & TGF- $\beta 1[\mathrm{pg} / \mathrm{ml}]$ & $5.38 \pm 4.46$ \\
\hline Baseline & $11.07 \pm 2.11$ & $109.97 \pm 2.01$ & $882.71 \pm 166.53$ & $5.92 \pm 7.08$ \\
\hline 2.5 & $10.91 \pm 2.04^{*}$ & $102.97 \pm 2.01$ & $811.40 \pm 216.57$ & $5.35 \pm 4.56$ \\
\hline
\end{tabular}

*Statistical significance of less than 0.05; SD - standard deviation.

IL-21 and TGF- $\beta 1$ are shown in Table 2. No statistically significant differences were noticed in the activation of T cells and concentrations of the cytokines IL-21 and TGF- $\beta 1$ prior to and 2.5 and $24 \mathrm{~h}$ after the start of treatment. A statistically significant increase in concentration of IL-10 between 2.5 and $24 \mathrm{~h}$ from the start of treatment was noticed. There were no significant differences in the concentration of the interleukin before the treatment and after its completion within the first $24 \mathrm{~h}$.

During the study, mild to moderate skin reactions (erythema) and itching of skin at the site of allergy vaccine were noticed. There were no serious adverse effects related to treatment.

\section{Discussion}

Currently, it is believed that allergen immunotherapy induces anergy of specific $T$ cells by showing a reduction in lymphocytes proliferation under the influence of stimulation with a specific allergen. The mechanism of this phenomenon is to be associated with increased synthesis of IL-10 and TGF- $\beta 1$ by specific Treg lymphocytes, and at a later stage also by B-cells and monocytes. Based on in vitro experiments it is known that CD4+ lymphocytes under the influence of high doses of immunogenic peptides, which are fragments of the allergen particles, lose their ability to proliferate and stimulate $\mathrm{B}$ lymphocytes. These cells under the influence of stimulation do not secrete IL-2, IL-4, IL-5, but they retain the ability to synthesize interferon $\gamma$ (IFN- $\gamma$ ). It was also found that VIT with the use of peptides, which are immunogenic fragments of phospholipase A2, a major allergen of bee venom, caused the T lymphocytes proliferation suppression and cytokine synthesis by the cells. In the second step, which led to a change in the functional phenotype of the cell, the reactivation takes place. Depending on the concentrations of the different cytokines in the microenvironment, the cells receive either a Th1 or Th2 phenotype. It has been shown that in the presence of IL-2 and IL-15, the cells are Th1 phenotype, while IL-4 promotes Th2 phenotype. The success of immunotherapy is therefore dependent on IL-10 synthesis [8-23].

This action demonstrates a clinical effect, which in case of desensitization to inhalant allergens is already observed a few weeks after starting immunotherapy. In case of immunotherapy for Hymenoptera venom, this effect is seen much earlier but its mechanism is not clear.

A very good clinical effect of the acquisition of tolerance to allergens of Hymenoptera during VIT has still not been explained immunologically. It is not known at what time after the start of immunotherapy, immunological tolerance is achieved, allowing for safe therapy, i.e. when it becomes deprived of sudden, severe anaphylactic reactions, particularly at the early phase of treatment, i.e. obtaining the maintenance dose when using fast and ultra-fast protocols. Currently, there are no known reliable indicators that can serve as parameters for assessing the effectiveness of VIT in terms of the risk of early-stage immunotherapy and severe adverse reactions during its term. There are no indicators which would be easy in the designation and possible in common, everyday use.

Memessier et al. stated that the change of Th2 lymphocytes to Th1 during VIT was combined with an increase in the amount of Treg and was quick between day 15 and 45 of treatment. They also observed that this phenomenon occurs faster and is more visible in patients with a lighter form of anaphylaxis (grade 1-2 according to Muller classification) after the Hymenoptera sting [24].

Pereira-Santos et al. showed a significant increase in the population of CD4+ Treg CD8brightFoxp3+ allergenspecific lymphocytes after 6 and 12 months of VIT. In addition, they observed a strong positive correlation of Treg lymphocytes changes and concentrations of IgG4 and IgE immunoglobulin influencing the course of allergic inflammation. The increase in the ratio of IgG4/IgE with an increase in the number of cells: CD4 + CD8brightFoxp3 + was observed. According to the authors, the correlations did not assume the causation of changes of regulatory cells, IgG4 and IgE, however they may be a consequence of changes in the population of Treg cells in the induction of tolerance [17].

In 2010, Bussmann et al. presented markers of early immunological response in the course of VIT by a rapid protocol (rush) when a full maintenance dose of $100 \mu \mathrm{g}$ was reached in 3 days, and within 5 days a cumulative dose of the Hymenoptera venom (311.54 $\mu \mathrm{g})$ was given. Researchers have proved an increased degradation of tryptophan in the serum of patients on the first day of VIT. The degradation of tryptophan is associated with suppression of T cell responses and the induction of immunological tolerance demonstrated in vitro and in vivo. A significant 
growth of ILT3 and ILT4 receptor expression on the surface of isolated monocytes was observed starting from the second day of VIT. ILT3/ILT4 are inhibitory receptors which negatively regulate the activity of cells presenting antigen (APCS) and have an immunosuppressive influence on T cells. It was on the $3^{\text {rd }}$ day that a significant increase in serum concentrations of IL-10 and the level of CAMP in monocytes isolated from peripheral blood was noted. It should be emphasized that the observed changes were a result of giving only 33.3 $\mu g$ of venom. The researchers suggest that the two markers may contribute to the early induction of protective mechanisms against allergic reactions while building the dose during VIT [25].

Riccio et al. evaluated the immunological activity of the serum concentrations of IL-10 and protein CTLA-4 (cytotoxic T lymphocyte-associated antigen-4), which is a negative regulator of $T$ cells activation before and after reaching a maintenance dose of allergen vaccines with venoms of different insects, during various immunotherapy protocols i.e.: the conventional, rush and ultra-rush ones. A significant decrease in the concentrations of CTLA-4 and a significant increase in IL-10 was observed. It is difficult to compare our results with Italian researchers' results due to different assessment time of the examined parameters [19].

Due to the fact that the sample in this research was relatively small, we are planning to continue the research on a bigger sample, potentially taking into account intracellular IL-10.

\section{Conclusions}

A 24-hour activation assessment of peripheral T lymphocytes CD4+ CD25+ Foxp3+ and serum concentrations of cytokines IL-10, IL-21 and TGF- $\beta 1$ during the first day of the Hymenoptera venom immunotherapy by ultrarush protocol does not show the significant dynamics of change of the examined parameters.

\section{Conflict of interest}

The authors declare no conflict of interest.

\section{References}

1. Fujita H, Soyka MB, Akdis M, et al. Mechanisms of allergenspecific immunotherapy. Clin Transl Allergy 2012; 2: 2.

2. Jutel M. Pathophysiologic basis for immunotherapy. Postep Dermatol Alergol 2003; 20: 125-9.

3. Kempiński K, Niedoszytko M. The effectiveness of immunotherapy in allergy to the Hymenoptera venom. Allergy Immun Asthma 2011; 16: 123-31.

4. Krishna MT, Ewan PW, Diwakar L, et al. Diagnosis and management of hymenoptera venom allergy: British Society of Allergy and Clinical Immunology (BSACI) guidelines. Clin Exp Allergy 2011; 41: 1201-20.

5. Krishna MT, Huissoon AP. Clinical immunology review series: an approach to desensitization. Clin Exp Immunol 2010; 163: 131-46.
6. Yacoub MR, Incorvaia C, Caminati M, et al. Immune mechanisms of allergen-specific immunotherapy. Open Immunol J 2012; 5: 47-52.

7. Grad A, Jung A, Stankiewicz W, et al. The answer of selected immunological parameters during subcutaneous specific immunotherapy and sublingual specific immunotherapy. Allergol Info 2009; 4: 22-9.

8. Moote W, Kim H. Allergen-specific immunotherapy. Asthma Clin Immunol 2011; 7 Suppl. 1: 55-61.

9. Ozdemir C, Kucuksezer UC, Akdis M, et al. Mechanisms of immunotherapy to wasp and bee venom. Clin Exp Allergy 2011; 41: 1226-34.

10. Song WJ. Mechanisms of allergen-specific immunotherapy. KAAACI Annual International Congress and East Asia Allergy Symposium, Alpensia Resort, Gangwon-do, November 13, 2012; S105-111.

11. Akdis CA, Adkis M. Mechanisms of allergen-specific immunotherapy. J Allergy Clin Immunol 2011; 127: 18-27.

12. Cichocka-Jarosz E, Brzyski P, Lis G, et al. Diagnostics and immunotherapy in children with allergy to the Hymenoptera venom (VIT) in Poland - what does the compliance with international guidelines look like in practice? Przegl Lek 2010; 67: 1-5.

13. Cichocka-Jarosz E, Diwakar L, Brzyski P, et al. Congruence of the current practices in Hymenoptera venom allergy patients in Poland with EAACl guidelines. Arch Med Sci 2011; 7: 832-9.

14. Dowbór-Dzwonka A, Cegła B, Filanowicz M, et al. Supersensitization to the Hymenoptera venom. Hygeia Public Health 2012; 47: 157-63.

15. Dreschler K, Bratke K, Petermann S, et al. Impact of immunotherapy on blood dendritic cells in patients with Hymenoptera venom allergy. J Allergy Clin Immunol 2011; 127: 487-94.

16. Duan W, So T, Mehta AK, et al. Inducible CD4+LAP+Foxp3 regulatory T cells suppress allergic inflammation. J Immunol 2011; 187: 6499-507.

17. Pereira-Santos MC, Baptista AP, Melo A, et al. Expansion of circulating Foxp3+CD25 bright $C D 4+T$ cells during specific venom immunotherapy. Clin Exp Allergy 2007; 38: 291-7.

18. Przybilla B, Ruëff F. Insect stings. Dtsch Arztebl Int 2012; 109: 238-48.

19. Riccio AM, Saverino D, Pesce G, et al. Effects of different up-dosing regimens for hymenoptera venom immunotherapy on serum CTLA-4 and IL-10. PLoS One 2012; 7: e37980.

20. Sanz C, Isidoro-Garcia I, Davila I. Modulation of the serum cytokine expression pattern in Hymenoptera allergic patients treated with specific venom immunotherapy. Open Immunol J 2012; 5: 13-9.

21. Patella V, Florio G, Giuliano A, et al. Hymenoptera venom immunotherapy: tolerance and efficacy of an ultrarush protocol versus a rush and a slow conventional protocol. J Allergy 2012; 2012: 192192.

22. Taylor A, Verhagen J, Blaser K, et al. Mechanisms of immune suppression by interleukin-10 and transforming growth factor-beta: the role of T regulatory cells. Immunology 2006; 117: 433-42.

23. Jutel M, Akdis M, Blaser K, et al. Are regulatory T cells the target of venom immunotherapy? Curr Opin Allergy Clin Immunol 2005; 5: 365-9.

24. Memessier E, Brinbaum J, Dupuy P, et al. Ultra-rush venom immunotherapy induces differentia $T$ cell activation and regulatory patterns according to the severity of allergy. Clin Exp Allergy 2006; 36: 704-13.

25. Bussmann C, Xia J, Allam JP, et al. Early markers for protective mechanism during rush venom immunotherapy. Allergy 2010; 61: 1558-65. 